\title{
EDUCATION AND TRAINING Evaluation of training programmes mapped to the new internal medicine curriculum
}

\author{
Authors: Jonathan Birns, ${ }^{\mathrm{A}}$ Claire Mullender, ${ }^{\mathrm{B}}$ Irene Balch, ${ }^{\mathrm{C}}$ Catherine Bryant ${ }^{\mathrm{D}}$ and Andrew Deaner ${ }^{\mathrm{E}}$
}

In preparation for the internal medicine training (IMT) programme introduced in 2019 , the core medical training (CMT) programme in London was made 'IMT-ready' in 2018 by creating new rotations that reflected the compulsory requirements of the first 2 years of the IMT curriculum, including provision of the requisite number of critical care placements. Core medical trainees completed posts within the 'IMT-ready' programme between August 2018 and August 2019, during which time the trainee experience was evaluated. A total of 497 responses were received. Of these, $96 \%$ of trainees were on an 'acute unselected take' on-call rota, $79 \%$ were able to attend outpatient clinics, $80 \%$ had the opportunity to practise procedural skills and $88 \%$ had the opportunity to apply palliative care skills. Clear areas for improvement were identified that predominantly focused on the need to optimise trainee attendance of outpatient clinics and the number of patients seen during an acute take. With respect to future career intentions, only $63 \%$ of trainees planned on applying to a group 1 (with general medicine) higher medical specialty. Thematic analysis of trainees in critical care placements highlighted an appreciation of the level of senior support, feeling well integrated into the team, a positive experience of induction and excellent opportunities for performing procedures.

KEYWORDS: Training programmes, internal medicine, IMT, curriculum

DOI: $10.7861 / f h j .2019-0060$

\section{Introduction}

National postgraduate educational agendas for physicians, particularly the Shape of Training review and Future Hospital

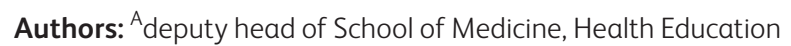
England, London, UK and consultant in stroke medicine, geriatrics and general medicine, St Thomas' Hospital, London, UK; ' ${ }^{\text {medical }}$ education fellow, Health Education England, London, UK; ' ${ }^{\text {service }}$ delivery manager, Health Education England, London, UK; ${ }^{\mathrm{D}}$ deputy head of School of Medicine, Health Education England, London, UK; Ehead of School of Medicine, Health Education England, London, UK
Commission report, set out a framework for refocusing training towards internal medicine with generalist skills relevant for an ageing population with increasing multimorbidity. ${ }^{1-3}$ As such, a new model for physician training has been introduced in 2019, consisting of 7 years of post-foundation level training, leading to a certificate of specialist training in internal medicine with a specialty. ${ }^{4}$ The first 3 years of this programme have been defined as internal medicine training (IMT) stage 1 (superseding 2 years of core medical training (CMT)), and the next 4 years of IMT stage 2 will supersede the current medical higher specialist training programmes and be divided into 'group 1' specialties that will dual train with internal medicine and 'group 2' specialties that will not. ${ }^{4}$

The purpose of the IMT stage 1 curriculum is to produce doctors with the generic professional and clinical capabilities to manage patients presenting with a wide range of general medical symptoms and conditions, and to recognise, assess and care for acutely unwell patients. As such, it includes mandatory training in the 'acute unselected take', critical care, palliative care and outpatient clinics. IMT doctors learn in a variety of settings using a range of methods, including workplace-based experiential learning, formal postgraduate teaching and simulation-based education, and are assessed by their 'capabilities in practice'. ${ }^{5}$

In preparation for the first year of the IMT programme commencing in August 2019, the CMT programme in London was made 'IMT-ready' in August 2018 by creating new rotations that reflected the compulsory requirements of the first 2 years of the IMT curriculum, including provision of the requisite number of critical care placements. This reorganisation was made possible by successful liaison and collaboration between the School of Medicine, training programme directors (TPDs), training committees of IMT and medical specialties, and local trusts, along with decommissioning and recommissioning of some posts within the same funding envelope. ${ }^{6}$ CMT doctors completed posts within the 'IMT-ready' programme between August 2018 and August 2019, during which time the trainee experience was evaluated in order to assess how curricular requirements were being met, and to identify areas for improvement and gauge career intentions to help with workforce planning.

\section{Methods}

An interdisciplinary working group of educationalists and physicians from various medical specialties developed an electronic survey tool to gain insight into the trainee experience of various aspects of the IMT curriculum including 'acute unselected take', outpatient clinics, opportunities for procedural 
skill development, palliative care experience and critical care placements. Overall trainee satisfaction, educational supervisor support and future career plans were also assessed. The survey was sent to all 570 CMT doctors in London on three occasions (November; March; July) over a 1-year period between August 2018 and August 2019 with trainees being informed that analysis of the results would be disseminated to facilitate quality improvement of the IMT programme.

The survey incorporated questions requiring 'Yes/No' responses, ratings on a five-point Likert scale (very poor; poor; neither good nor bad; good; very good) and free-text feedback. Records of freetext feedback were transcribed into Microsoft Excel spreadsheets (version 16.25) with each response being kept as a separate datum point. All text was thematically analysed. Themes were developed by iteratively reading and regrouping the data. Each coded theme was discussed and checked; any discrepancies were discussed and if necessary re-evaluated for alternatives. Once themes were finalised, the data were rechecked and if necessary recoded as appropriate. A single response could be, and often was, coded against multiple themes. Thematic analysis was employed as a method of evaluating data in view of the opportunity to "generate interesting findings beyond the specific research questions for which the study was designed'?

\section{Results}

Four-hundred and ninety-seven responses were received from trainees in placements across 17 medical specialties. Sixty-four per cent of responses were from trainees placed at university teaching hospitals and $36 \%$ were from trainees placed at district general hospitals (DGHs). The overall experience and educational value of their placement was rated as good or very good by $\geq 70 \%$ of respondents, with no significant difference between university teaching hospitals and DGHs (Fig 1). Almost all (99\%) trainees were able to identify their educational supervisor and $78 \%$ of trainees had met with their educational supervisor within 4 weeks of commencing a post (Fig 2). Ninety-six per cent of trainees were on an "acute unselected take' on-call rota, $79 \%$ were able to attend outpatient clinics, $80 \%$ had the opportunity to practise procedural skills and $88 \%$ had the opportunity to apply palliative care skills during their rotation. Trainees fed back a need to improve on the number of clinics they could attend and the number of patients seen during an acute take (Table 1). With respect to future career intentions, $63 \%$ planned on applying to a group 1 specialty, $24 \%$ planned on

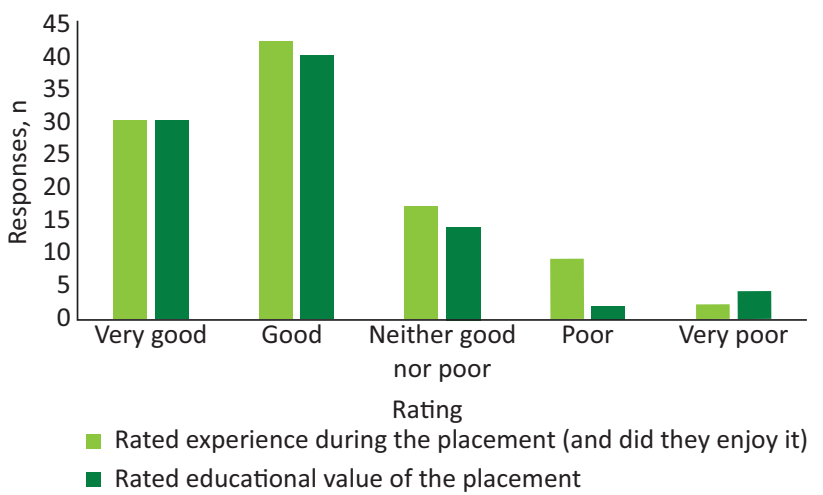

Fig 1. Overall experience and educational value of IMT placements.

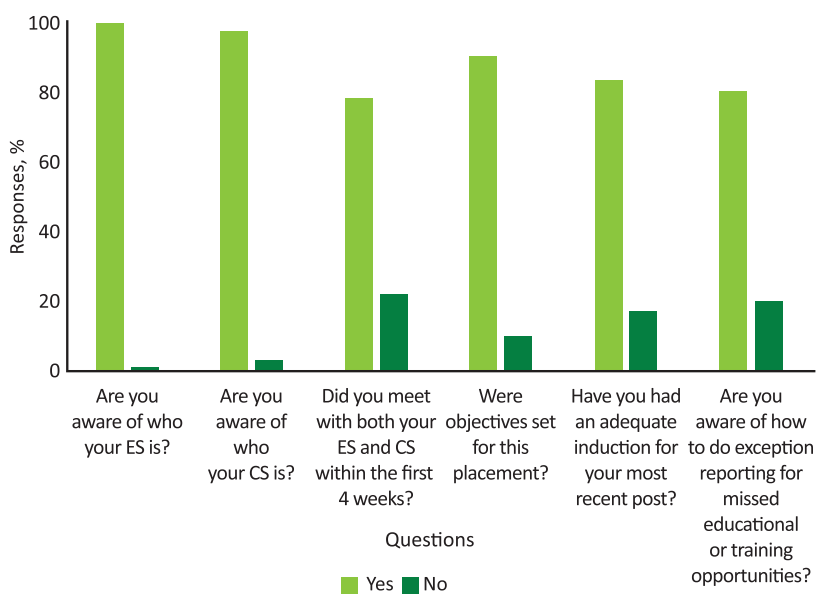

Fig 2. Trainee responses regarding induction to their roles. ES = educational supervisor; CS = clinical supervisor.

applying to a group 2 specialty, $7 \%$ did not want to continue working in a medical specialty, and the remainder wanted to take time out of training without specifying subsequent intentions.

Eighty-three survey responses were received from trainees in critical care placements. Of these trainees, $92 \%$ were on the critical care on-call rota and took part in outreach services. The overall experience and educational value of the placement was rated as good or very good by $80 \%$ of trainees, and $86 \%$ of trainees reported gaining experience in palliative care and endof-life care decisions. Thematic analysis highlighted four major themes of an appreciation of the level of senior support; feeling well integrated into the team; a positive experience of induction; and excellent opportunities for performing procedures.

\section{Discussion}

Trainees undertaking 'IMT-ready' programmes had a high level of opportunity to attain completion of curricular components

Table 1. Trainee feedback on areas to improve

\begin{tabular}{ll}
$\begin{array}{l}\text { Area } \\
\text { Number of clinics per month undertaken by }\end{array}$ & $\mathbf{n}(\%)$ \\
IMTs & \\
$1-2$ & $186(61)$ \\
$2-3$ & $77(25)$ \\
$4-5$ & $36(12)$ \\
$\geq 6$ & $7(2)$ \\
Number of patients seen by IMTs during 'acute & \\
unselected take' & \\
$<5$ & $26(10)$ \\
$5-9$ & $182(72)$ \\
$10-15$ & $43(17)$ \\
$>15$ & $2(1)$ \\
\hline IMT = internal medicine training doctor. &
\end{tabular}




\section{Box 1. Top tips for getting internal medicine} training ready

Ensure training programmes provide:

> 'acute unselected take' to meet curricular requirements of 500 patients in 3 years

outpatient clinics to meet curricular requirements of 80 clinics in 3 years

critical care placements

opportunities to practise procedural skills

opportunities to apply palliative care skills

adequate induction for trainees and trainers.

Ensure trainees meet with their educational supervisor within 4 weeks of commencing a post.

and the majority of trainees were satisfied with the training experience. Exposure to critical care also enhanced procedural skill development supporting the practical capabilities needed to manage acutely unwell patients. Historically, trainees have found 'sign off' and self-reported confidence for procedures difficult and central venous cannula insertion must now be with ultrasoundguidance in a designated environment such as an intensive care unit. ${ }^{8,9}$ Lifesaving procedures can only be practised as procedural drills and reliably assessed if commonly performed, and so the value of critical care placements for IMT doctors appears important for their development of independence in this regard. ${ }^{10}$ Furthermore, this study showed IMT doctors working in critical care to feel well integrated into the team, providing a level of confidence for working effectively with critical care services as future medical registrars.

Clear areas for improvement were identified by doctors in 'IMT-ready' programmes that provide opportunities for constructive changes in the future (Box 1). These predominantly focused on the need to optimise trainee attendance of outpatient clinics and the number of patients seen by trainees during an acute take in order to meet the IMT curricular requirements of 80 outpatient clinics and 500 'acute take' patients respectively in 3 years. ${ }^{5}$ These issues will need considerable attention from TPDs, and represent a real challenge in an era when IMT doctors are managing an increasingly multimorbid patient population demanding more time from each inpatient clinical encounter. ${ }^{11}$

In planning IMT, the Royal College Physicians (RCP) projected that approximately $70 \%$ of physician trainees would apply to a group 1 medical specialty. ${ }^{4}$ The results of this survey suggest that a smaller percentage may wish to proceed immediately to a group 1 medical specialty and this has implications for workforce planning. Previous RCP data have suggested that acute medical specialties have proved less attractive with medical registrars feeling demoralised and undervalued. ${ }^{12,13}$ Indeed, the role of the medical registrar has been perceived as one of the most stressful in the hospital, deterring trainees from pursuing career paths that incorporate internal medicine. ${ }^{8}$ The Shape of Training review and IMT training programme, however, broadens acute medical responsibilities across a wider range of specialties with an aim of providing a more balanced workforce. ${ }^{14}$ Further work is likely to be required to optimise issues of morale and retention within internal medicine as the IMT programme is rolled out. ${ }^{8}$
The new IMT model for physicianly training is the most important change to medical training for a generation and evaluation of its implementation is crucial to its success. The strengths of this study pertain to the large number of trainees surveyed and the study methodology devised by an interdisciplinary project group of trainees and trainers that incorporated a mixed-methods evaluation. In addition, data were captured from trainees working across different clinical settings that represent a broad range of exposure within IMT.

Limitations of the study included the low total response rate of only 29\% (497 responses from 570 trainees surveyed three times) and the cross-sectional rather than longitudinal approach. The involvement of trainees in just one geographic area also limits the generalisability of the results across the UK. Survey response may also be skewed by self-selection bias, as colleagues with a particularly positive or negative experience may be most motivated to participate. However, with the aim of the study being to explore the effect of introducing IMT, appreciating both positive and negative experiences is informative and useful.

Mapping of the IMT curriculum to CMT in London resulted in the creation of posts that provided a positive trainee experience and identified areas for improvement to help meet curricular requirements. Ongoing assessment of career intentions of physicians in such training programmes may also help workforce planning for the future.

\section{References}

1 Department of Health. Delivering high quality, effective, compassionate care: Developing the right people with the right skills and the right values. A mandate from the Government to Health Education England: April 2016 to March 2017. GOV.UK, 2016. www.gov.uk/government/uploads/system/uploads/attachment_ data/file/559940/HEE_mandate_2016-17_acc.pdf

2 Future Hospital Commission. Future hospital: Caring for medical patients. Royal College of Physicians, 2013. www.rcplondon.ac.uk/ projects/outputs/future-hospital-commission

3 Shape of Training Review. Securing the future of excellent patient care. Shape of Training, 2013. www.shapeoftraining.co.uk/ static/documents/content/Shape_of_training_FINAL_Report. pdf_53977887.pdf

4 Joint Royal Colleges of Physicians Training Board. Shape of Training and the physician training model. JRCPTB. www.jrcptb.org.uk/newinternal-medicine-curriculum

5 Joint Royal Colleges of Physicians Training Board. Rough guide to internal medicine Training Guidance for training programme directors, supervisors and trainees. London: JRCPTB, 2019. www.jrcptb. org.uk/sites/default/files/Rough \% 20guide \% 20to \% 20IMT \% 20 3October \% 202019.pdf

6 Mcnulty M, Carty E, Chakravorty I et al. Creation of novel training programmes mapped to the Joint Royal Colleges of Physicians' Training Board Internal Medicine Stage 1 curriculum. FH] 2019;6(Suppl 1):128.

7 Yardley S, Irvine AW, Lefropy J. Minding the gap between communication skills simulation and authentic experience. Med Education 2013:47:495-510.

8 Tasker F, Newbery N, Burr B, Goddard AF. Survey of core medical trainees in the United Kingdom 2013 - inconsistencies in training experience and competing service demands. Clin Med 2014;14:149-56.

9 National Institute for Health and Care Excellence. Guidance on the use of ultrasound locating devices for placing central venous catheters: Technology appraisal guidance [TA49]. NICE, 2002. www. nice.org.uk/guidance/ta49 
10 Bould MD, Crabtree NA, Naik VN. Assessment of procedural skills in anaesthesia. Br ] Anaesth 2009;103:472-83.

11 Sommerville P, Lang A, Archer S, Woodcock T, Birns J. FORWARD (Feeding via the Oral Route With Acknowledged Risk of Deterioration): evaluation of a novel tool to support patients eating and drinking at risk of aspiration. Age Ageing 2019;48:553-8.

12 Blakey J, LeJeune I, Levy M et al. General medicine's recruitment crisis: what happened to all the heroes? BMJ 2013;346:f1812.

13 Royal College of Physicians. The medical registrar: empowering the unsung heroes of patient care. London: RCP, 2013.
14 Gowland E, Le Ball K, Bryant C, Birns J. Where did the acute medical trainees go? A review of the career pathways of acute care common stem (ACCS) acute medical trainees in London. Clin Med 2016;16:427-31.

Address for correspondence: Dr Jonathan Birns, Department of Ageing and Health, St Thomas' Hospital, Westminster Bridge Road, London SE1 7EH, UK.

Email: jonathan.birns@gstt.nhs.uk

\section{Consent and confidentiality in genomic medicine}

Genetic or genomic tests are increasingly used in everyday medical practice. Every clinical field will encounter such tests to a greater or lesser extent.

Published in 2019, this third edition by the Joint Committee on Genomics in Medicine provides updated guidance on the use of genetic and genomic information in the clinic. Health professionals from all areas of medicine need to know and understand how consent and confidentiality issues may arise, and to understand the potential ways in which the use of genomic tests may change the nature of the relationship between healthcare professionals and patients.

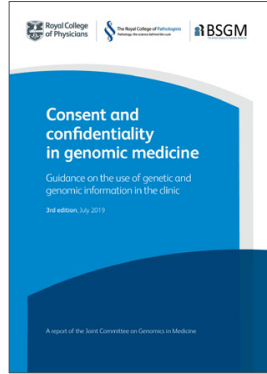

Download the guidance at: www.rcplondon.ac.uk/consent-confidentiality-genomic-medicine 